\title{
A INFÂNCIA NO LIMIAR: EIXO, INSPIRAÇÃO E \\ PRINCÍPIOS NA FORMAÇÃO CONTINUADA E PERMANENTE \\ DAS/OS PROFESSORAS/ES DA EDUCAÇÃO BÁSICA
}

\author{
Adriana A. Silva \\ Universidade Federal de Santa Catarina
}

\begin{abstract}
Resumo
O presente texto apresenta um relato de experiência abordando reflexões a cerca da infância como eixo e inspiração teórico metodológico na formação de professoras/es nos anos iniciais do Ensino Fundamental e na formação continuada na Educação Infantil. Parte de uma experiência de estágio no curso de Pedagogia da Universidade Federal de Santa Catarina/UFSC em uma escola estadual em Florianópolis à participação como assessora na formação continuada nas redes municipais de Educação Infantil de São José e Florianópolis, ambas formações voltadas ao eixos curriculares: brincadeiras, múltiplas linguagens e relações sociais e culturais, com foco no espaço e tempo na EI. Nestes movimentos formativos as/os professoras/es em exercício nas horas atividades apontam múltiplos e instigantes olhares para as relações entre ensino, pesquisa e extensão na universidade pública articuladas com a perspectiva deste dossiê sobre formação continuada, entrelaçando: as pesquisas, políticas e práticas.
\end{abstract}

Palavras chave: anos iniciais; educação infantil; formação de professoras/es.

\footnotetext{
${ }^{1}$ Adriana Silva: Pedagoga pela FE/Unicamp, Mestre em Multimeios (Cinema e Vídeo) do Instituto de Artes IA/Unicamp e Doutora em Educação pela FE/Unicamp, desde 2008 é pesquisadora do GEPEDISC - Culturas Infantis da FE Unicamp. Trabalha na formação continuada de professoras de Educação Infantil nas redes de São José, Florianópolis e como Professora substituta da disciplina Educação e Infância VIII (estágio nos anos iniciais) do curso de Pedagogia no Centro de Ciências da Educação/CED da Universidade Federal de Santa Catarina/UFSC.

Olh@res, Guarulhos, v. 2, n. 2, p.375-404 . Dezembro, 2014.
} 
A infância no limiar: eixo, inspiração e princípios na formação continuada e permanente das/os professoras/e da educação

\title{
THE CHILDHOOD ON THE BRINK: SPINDLE, INSPIRATION AND THE PRINCIPLES OF CONTINUING EDUCATION AND PERMANENT THE TEACHING OF BASIC EDUCATION
}

\begin{abstract}
This paper presents an experience report addressing reflections about the childhood as axis and methodological theoretical inspiration in the training of teachers in the early years of elementary school and continuing education in kindergarten. The placement experience in pedagogy courses at UFSC in a public school in Florianopolis looks over the continuing education in municipal networks Childhood Education from São José and Florianópolis, both formations aimed at curricular areas: play, multiple languages and social and cultural relations, focusing on space and time in EI. These formative movements with the teachers in exercise activities in the hours and multiple point provocative looks for relationships between teaching, research and extension in the public university articulated at the prospect of this dossier on continuing education, lacing : research, policy and practice .
\end{abstract}

Keywords: early years; children's education; formation of teachers.

Olh@res, Guarulhos, v. 2, n. 2, p.375-404 . Dezembro, 2014. 
A infância no limiar, como eixo e inspiração nos processos de formação de professoras/es, parte da minha experiência docente no curso de Pedagogia ${ }^{2}$ da Universidade Federal de Santa Catarina, que deste 2009, em sua última reformulação curricular, tem como eixo: as relações entre educação e infância, coordenação dos processos educativos e pesquisa, reafirmando a docência como base da formação, para a educação infantil e os anos iniciais, tendo como principio da sua matriz curricular priorizar os sujeitos deste processo, as crianças.

No limiar, tendo como princípio lançar olhares a este "lugar onde fervilha a imaginação" referindo-se a uma metodologia Benjaminiana (BARRENTO, 2013) tendo a infância e suas possíveis constelações, também inspiradas pelas Reflexões sobre a Criança, o Brinquedo e a Educação (BENJAMIM, 2002) e suas relações com a educação e a escola como um caldeirão de possibilidades para pensarmos a formação de professoras/es, da formação de base no curso de Pedagogia, passando pela continuada e permanente das/os professores na escola, ou nas horas atividades $^{3}$ das redes municipais.

Cabe ressaltar que minha formação como pedagoga, professora de educação infantil e de cursos de Pedagogia no ensino superior, lugar que atuo nos últimos anos especialmente com estágios, como "criancista e criancóloga" (FARIA, 2007) busca sempre articular a pesquisa com a política, tendo a militância pelo direito a infância como indispensável na nossa permanente dimensão formativa, e que esta formação foi constituída fundamentalmente no GEPEDISC (Grupo de estudos e pesquisas em diferenciação sócio-cultural) - Culturas Infantis da Faculdade de Educação da Unicamp.

E nas camadas deste artigo, apresento em um primeiro momento a experiência do estágio nos anos iniciais do curso de Pedagogia da UFSC, através da disciplina "Educação e Infância VIII: exercício da docência nos anos iniciais" que ao longo dos últimos 10 anos vem sendo construída na

\footnotetext{
${ }^{2}$ Disponível para consulta em: http://www.ced.ufsc.br/pedagogia/curriculo.htm Acesso em 20.05.2014.

${ }^{3}$ Horas-atividades, é o tempo disponível para formação, estudo e planejamento dentro da carga horária de trabalho das professoras e professores das redes de Florianópolis e São José.
}

Olh@res, Guarulhos, v. 2, n. 2, p.375-404 . Dezembro, 2014. 
relação de pesquisa, ensino e extensão do GEPIEE (Grupo de Estudos e Pesquisas Educação, Infância e Escola). Experiência recente e nos limiares: com o grupo e na escola estadual campo de estágio, escola que traz uma intensa história de formação, de politização docente, resistências em territórios precarizados de Florianópolis, a bela ilha da magia, com suas belezas naturais e também complexas contradições estruturais.

E no segundo momento, trago experiências e reflexões sobre a formação continuada nas redes de Educação Infantil dos municípios de São José e Florianópolis, buscando tecer análises na interlocução das relações entre ensino, pesquisa e extensão da universidade articuladas com a perspectiva deste dossiê: Formação Continuada e as Pesquisas, Políticas e Práticas.

No estágio dos anos iniciais na escola, apresento reflexões sobre o foco do direito à infância na escola, na relação da professora regente (como co- formadora) e as estagiárias, estas possíveis criadoras de novas práticas docentes que enfatizem este direito das crianças. Cabe destaque a abertura e expectativa das professoras em exercício na escola com a experiência do estágio, por inovação e possibilidades de conhecerem novas práticas pedagógicas que as ajudem no trabalho cotidiano com as crianças. As escolas que participam da prática docente da UFSC nos anos iniciais, têm como critérios de participação, estarem abertas/disponíveis/desejosas do estágio configurando-se como um campo de formação continuada, em especial duas das três escolas que se constituem como campo de estágio nos anos iniciais do curso de Pedagogia da UFSC, fizeram parte do Fórum de Educação do Morro do Maciço da Cruz, que brevemente apresento neste texto, uma rica e inspiradora experiência histórica de formação de professores em Florianópolis.

Também trago para o artigo algumas vozes que ressoam em mim, como professora em constante formação, salientando os riscos dos limiares, que transgridem as fronteiras de gêneros e métodos, mas considerando imprescindível ouvir as vozes das professoras, busco um diálogo com as professoras dos $1^{\circ}$ e $2^{\circ}$ anos, ambas provenientes da Educação Infantil atuando com os anos iniciais e contagiando a escola nos Olh@res, Guarulhos, v. 2, n. 2, p.375-404 . Dezembro, 2014. 
pequenos detalhes do cotidiano, com a maravilha da infância, assim como lanço alguns olhares, a partir delas, sobre a formação do PNAIC (Programa Nacional de Alfabetização na Idade Certa) do Governo Federal e a formação continuada destas professoras em exercício.

Porém destaco que as professoras inspiradoras destas reflexões, não têm estas possibilidades de deslocamento de atuação garantido por um possível ingresso em uma carreira no magistério que prevê o trabalho na educação infantil e nos anos iniciais, ambas possuem trajetórias de exercício docente como ACT's (Admitido em caráter temporário), passando do estado para o município e vice-versa e da educação infantil para os anos iniciais por contingências, configurando-se em mais um nó da carreira docente, tanto na Educação Infantil como nos anos iniciais.

Nesta perspectiva dos impasses e desafios da carreira docente da/o professor/a de educação infantil e também dos anos iniciais, de criança, da formação inicial a permanente destes profissionais, cabe destacar as reflexões levantadas por Tizuko M. Kishimoto no artigo Pedagogia e a formação de professores(as) de Educação Infantil (2005) que analisou cursos de Pedagogia da rede privada para problematizar o perfil híbrido e também bem fragilizado dos cursos que visam formar para a docência na educação infantil e nos anos iniciais, assim como especialista, o pedagogo.

Também do ponto de vista das fragilidades e contradições, cabe ressaltar que as escolas da rede estadual no município de Florianópolis se configuram como núcleos de resistência, amparadas do ponto de vista de políticas de formação, segundo as professoras por poucos programas do governo federal, já as municipais apresentam diferentes políticas de formação. Sendo assim busco abordar diversas facetas da formação de/as professores/as: do curso de Pedagogia, na Escola formando as e com estagiárias e na formação continuada como as profissionais da rede municipal.

Em relação à formação continuada das professoras de educação infantil, a partir das experiências com as redes municipais: de São José e Florianópolis, as propostas de formação também podem ser analisadas e valorizadas na perspectiva da resistência, pois em tempos sombrios de Olh@res, Guarulhos, v. 2, n. 2, p.375-404 . Dezembro, 2014. 
A infância no limiar: eixo, inspiração e princípios na formação continuada e permanente das/os professoras/e da educação

avanço neoliberal, apostilas e avaliação de desempenho com as crianças pequenas, as propostas e investimento político de formação destas redes, nos limiares da construção e criação coletiva de seus currículos, estas redes vêem buscando através de parcerias estabelecidas de formas distintas, mas complementares, relações com a Universidade, suas/seus pesquisadores, amalgamando a pesquisa, com a política e as práticas pedagógicas.

Ainda na relação da formação continuada e as resistências, atrelando aos nós e contradições destacadas anteriormente, é interessante apontar as reflexões levantadas por Maria Letícia B. P. Nascimento no artigo As políticas públicas de educação infantil e a utilização de sistemas apostilados no cotidiano de creches e pré-escolas públicas (2012), que a autora destaca nos motivos para a crescente e preocupante adoção dos SPE (Sistemas privados de ensino) os desafios na responsabilidade das redes públicas em providenciar a formação continuada qualificando seu corpo docente.

Qualificar seu corpo docente seria o objetivo geral das propostas de formação das referidas redes abordadas neste artigo, conforme as Diretrizes e Orientações Curriculares (FLORIANÓPOLIS, 2012 e SÃO JOSÉ, 2001 e 2008), dentro de uma intencionalidade pedagógica que atenda os direitos, interesses e possibilidades da educação integral de suas crianças e suas respectivas infâncias, respeitando as especificidades concretas, do tempo e espaço em que estão inseridas, assim como de suas/seus profissionais, professoras/es em formação continuada e permanente, buscando criar as condições de um prática pedagógica que tenha a consciência da indissociabilidade do educar e do cuidar, assim como dos princípios políticos, éticos e estéticos indispensáveis na ação educativa.

A experiência do estágio nos anos iniciais: o direito à infância na escola como principio formativo

A disciplina obrigatória as/aos estudantes de Pedagogia da UFSC "Educação e Infância VIII: exercício da docência nos anos iniciais" com Olh@res, Guarulhos, v. 2, n. 2, p.375-404 . Dezembro, 2014. 
carga horária de 144 hrs/aula, sendo oferecida na $8^{\circ}$ fase do curso é o momento da experiência com a escola de ensino fundamental, coordenado pela Profa Maria Batista Serrão ${ }^{4}$ proporciona em sua articulação uma experiência para além do estágio obrigatório dos currículos de Pedagogia, o projeto desta disciplina em especifico, prevê uma experiência mais qualitativa que possa também ser vivenciada na perspectiva do Direito à Infância na escola, uma vez que o curso de Pedagogia da UFSC tem em seu eixo a Infância e suas relações com a Educação.

A disciplina citada é basicamente organizada em três momentos: observação participante, planejamento e exercício docente, posteriormente elaboração de relatórios e seminários de 'avaliação', com a intencionalidade de compartilhar as experiências em campos distintos de estágio, no momento em três escolas públicas de Florianópolis (duas estaduais e uma municipal), cada uma supervisionada por uma professora e tendo um conjunto de no máximo 12 estudantes do curso de Pedagogia, que se dividem geralmente em duplas, ficando cada dupla em uma sala, também tendo a oportunidade de exercer a dupla docência.

A prática docente também é oferecida concomitantemente com as disciplinas: Didática II: processos de ensino nos anos iniciais; Da Escolarização, organização dos processos coletivos do trabalho escolar e Pesquisa em Educação III: orientação ao TCC, buscando uma maior integração dos conteúdos que subsidiam as práticas pedagógicas na escola e fazendo a ponte com a finalização do curso com o TCC (trabalho de conclusão do curso) que vem na próxima e última fase do curso de Pedagogia na UFSC.

O direito à infância na escola configura-se como um principio político pedagógico que é trabalhado desde a $1^{\circ}$ fase do curso e perpassa todas as disciplinas do eixo Educação e Infância, presentes em todos os semestres e estando nos limiares entre as especificidades da Educação Infantil e as lutas, conquistas e possibilidades de trabalho com a infância nos anos iniciais do ensino fundamental, configurando-se em um

\footnotetext{
${ }^{4}$ Pesquisadora do GEPIEE/UFSC e dos Grupo de Estudos e Pesquisas sobre Formação do Educador GEPAPe e sobre Atividade Pedagógica GEPEFE, ambos vinculados à USP.
}

Olh@res, Guarulhos, v. 2, n. 2, p.375-404 .Dezembro, 2014. 
A infância no limiar: eixo, inspiração e princípios na formação continuada e permanente das/os professoras/e da educação

importante movimento para uma Pedagogia de 0 a 10 anos, que contemple uma educação básica com ênfase nos sujeitos de direitos, as crianças.

Considerando que historicamente a escola é o espaço e o tempo do 'aluno', a questão da infância e suas crianças, é uma temática que ainda vem sendo pouco estudada e problematizada no campo da educação, a tese "Infância e Escola: uma relação marcada por preconceitos" (FE, UNICAMP, 2000) de Jucirema Quinteiro, docente do curso de Pedagogia da UFSC, é um marco e dá subsídios para uma série de pesquisas, práticas e políticas desenvolvidas posteriormente no GEPIEE, algumas delas sistematizadas e compartilhadas na publicação "Participar, brincar $e$ aprender: exercitando os direitos da criança na escola" (2007), bem como em diversas dissertações e teses sobre as temáticas que envolvem as múltiplas e complexas relações das crianças na escola de ensino fundamental.

Em especial cabe o destaque a recente dissertação de mestrado " $O$ direito à infância na escola: o estágio docente como campo de pesquisa" de Maria Eliza C. Pimentel, (CED/UFSC, 2014) que em um estudo minucioso analisa os limites e as possibilidades do direito à infância na escola, em uma perspectiva histórica e sociológica, elegendo os relatórios de estágio do curso de pedagogia da UFSC dos últimos 12 anos e apontando que as crianças gradativamente são reconhecidas como portadoras de direitos na sociedade, elas contagiam a escola de alegria, mas ainda esbarram nas cristalizadas práticas adultocênticas, plenas de hierarquia e resistência a conteúdos formativos que coloquem as crianças em relação de participação e construção do seu próprio processo formativo. ${ }^{5}$

\footnotetext{
${ }^{5}$ No contexto do estágio tivemos a oportunidade de participar de um dos momentos de formação continuada com as professoras dos anos iniciais, acompanhamos a palestra da Professora Zóia Ribeiro Prestes (Importante pesquisadora de L. S. Vigotski referencia fundamental da teoria histórico cultural) no XXIII Encontro Estadual dos Supervisores Escolares de Santa Catarina, intitulada "Direito a aprendizagem: repensando a escola", onde a pesquisadora embora não tratou diretamente da infância, ao discutir os direitos na escola, problematizou a necessidade de repensarmos a escola, suas formas e processos de exclusão que não respeita as crianças e suas infâncias. A pesquisadora ao tecer estas criticas indicou para suscitar mais reflexões o documentário Quando sinto que já sei de Antonio Lovato, Brasil, 2014.

Disponível na integra em: https://www.youtube.com/watch?v=HX6P6P3x1Qg Acesso em 25/10/2014.
}

Olh@res, Guarulhos, v. 2, n. 2, p.375-404 . Dezembro, 2014. 
Em seguida apresento alguns registros, episódios que problematizam a experiência da formação de professoras neste contexto, tanto do ponto de vista inicial no curso de pedagogia, como da continuada das professoras em exercício, não com a intenção de problematizar o estágio em si, mas sim o tomando como um dos possíveis espaços de encontro formativo e refletindo sobre as relações da formação com as pesquisas, políticas e práticas.

\section{Ser professora no campo minado: "Você é do conselho tutelar?"}

Em uma das tardes de observação na escola, acompanhando as alunas/estagiárias no $5^{\circ}$ ano 'problema', após uma meia hora em sala uma criança, se dirige a mim: "Você é do conselho tutelar?", disse que não, que era professora das estagiárias, que era da universidade, a criança disse: "Ah, tá!" Este episódio me remeteu a diversos relatos das professoras da coordenação pedagógica da presença do conselho tutelar na vida destas crianças e no cotidiano da escola.

Este $5^{\circ}$ ano 'problema' o melhor seria, difícil e desafiador, atualmente configurou-se nesta minha experiência de estágio como o campo minado dos anos iniciais, com crianças de diferentes idades e níveis de aprendizagem, nos limiares entre a infância e pré-adolescência, a resistência e permanência na escola, ao abandono e entrada em possíveis caminhos e descaminhos da marginalidade presentes em todos os grandes centros urbanos, como também em Florianópolis.

Esta escola também se situa em um importante limiar entre as contradições e possibilidades, conforme tive a oportunidade de vivenciar no estágio e também de estar se aproximando de uma bibliografia produzida em Florianópolis sobre territórios precarizados, formação docente e politização. No prefácio do livro "Formação continuada e politização docente: escola e universidade na luta pela educação no Maciço da Cruz - Florianópolis” (2013) Célia R. Vendramini, também

\footnotetext{
${ }^{6}$ A referência de cunho aparentemente pejorativo, configura-se mais como uma sala desafio para a escola neste momento, por conta das razões citadas em seguir na continuidade do texto.
}

Olh@res, Guarulhos, v. 2, n. 2, p.375-404 .Dezembro, 2014. 
A infância no limiar: eixo, inspiração e princípios na formação continuada e permanente das/os professoras/e da educação

docente do CED (Centro das Ciências da Educação) da UFSC, nos apresenta,

O livro tem como propósito registrar e refletir sobre experiências políticas e pedagógicas de escolas situadas no maciço do Morro da Cruz. Não são escolas "modelos", são escolas públicas que atendem crianças e jovens dos morros de Florianópolis, os quais enfrentam problemas relacionados a violência, tráfico de drogas e difíceis condições de vida e de trabalho. Algumas escolas foram abandonadas e fechadas, as demais contam com financiamento mínimo do Estado. A rotatividade dos professores é grande, bem como a insegurança, a elevada carga de trabalho, os contratos temporários e os afastamentos em função do adoecimento. É neste contexto que emergem experiências coletivas superadoras, relativas à gestão democrática das escolas, à eleição de diretores, à construção coletiva do Projeto Político Pedagógico, ao ensino articulado com o contexto de vida das crianças e jovens, como as relações étnico-raciais e as questões da pacificação e democratização. (VENDRAMINI, p. 13)

Este livro organizado por Luciana P. Marcassa, Fábio M. Pinto e Jéferson S. Dantas, professores-pesquisadores da UFSC em diálogo e com a participação ativa de professores das escolas do morro do Maciço da Cruz, traz uma experiência de formação continuada e politização docente, abrangendo o período de constituição da Comissão de Educação do Fórum do Maciço da Cruz (CE/FMMC) em outubro de 2000, iniciando as atividades em 2001 até 2011, denotando uma trajetória de formação em serviço de dez anos.

Uma experiência de formação continuada nos limiares da politização docente, que atenda as necessidades concretas de escolas situadas em territórios de precarização, onde dar aulas, fazer estágio, trabalhar cotidianamente é estar em um campo minado permanente e a política, a produção de conhecimento histórico crítico sobre as desigualdades e perversidades no campo da educação pública é imprescindível.

Nesta perspectiva a escola hoje, neste momento ainda com um grupo ativo de professoras que fizeram parte da Comissão de Educação do FMMC, mas sem grandes articulações coletivas da formação continuada junto a outras escolas, iniciou com otimismo o ano eletivo de 2014, com um quadro de professoras efetivas para os anos iniciais após anos com uma Olh@res, Guarulhos, v. 2, n. 2, p.375-404 . Dezembro, 2014. 
grande rotatividade de ACT's, bem como acolheu o estágio de pedagogia enfatizando a intencionalidade de fazer uma co-formação, consciente dos limites e das possibilidades, mas compreendendo que a educação básica se alimenta e articula (ou menos deveria) o ensino superior em seus cursos de formação de professores, seja na pedagogia e/ou nas licenciaturas.

Esta perspectiva da professora regente ativa no processo, assim como da escola como co-formadora, vem sendo experimentada e construída no processo de aproximação da UFSC com a escola, a partir de seminários realizados no inicio e no final do semestre, a fim de promover encontros de apresentação do campo de estágio, perspectivas e expectativas, bem como de socializações do exercício docente pelas estagiárias e avaliações no final do processo, assim como eventuais reuniões de planejamento compartilhado no decorrer do semestre.

Também a fim de construir esta relação de formação de base, no estágio, com a continuada das professoras em exercício, nas condições dadas, em serviço, no compartilhamento das práticas pedagógicas, a escola proporciona no inicio do ano, uma visita a comunidade, a fim de conhecer os morros que atende, atividade que as estagiárias neste ano juntaram-se ao corpo de professoras efetivas recém chegadas à escola, bem como as/os antigos que estão em vias de se aposentar e o grupo após a visita pode refletir e dialogar sobre as especificidades, contradições e possibilidades de trabalho pedagógico da escola para este ano, com estas crianças e jovens e estas/es professoras/es, em uma difícil, mas importante dialética do concreto e na explosão do real.

Olhares transgressivos para a infância como eixo e possibilidade: indissociabilidade do educar e cuidar

Duas questões me chamaram a atenção no trabalho pedagógico nesta escola com as professoras e as crianças, uma primeira que seria a forma como a infância relaciona-se como um princípio humanizador das relações, na minha hipótese refletindo a perspectiva histórico-cultural presente na formação das professoras, no sentido apontando por Suely Olh@res, Guarulhos, v. 2, n. 2, p.375-404 . Dezembro, 2014. 
Mello em "Infância e humanização: algumas considerações na perspectiva histórico-cultural" (2007) que a autora enfatiza o "processo de humanização como processo de educação' (p. 88) e complementar a isto uma segunda questão que é a indissociabilidade entre o educar e o cuidar, tão evidente na Educação Infantil, o cuidar e o educar nos anos inicias, na minha interpretação é possível na perspectiva do direito a infância na escola, tendo como principio que antes de estar aluno, existe uma criança sujeito de direitos, que merece ser cuidada e respeitada.

Porém nos anos iniciais, as relações ainda são marcadas por preconceitos, parafraseando o título da tese da socióloga Jucirema Quinteiro (2000), “Escola e Infância: uma relação marcada por preconceitos" e transgredir esta relação marcada historicamente por preconceitos implica mudar as formas de ver, olhar as crianças, suas necessidades e possibilidades, considerando seus contextos de vida marcados por perversas desigualdades - como a miséria, famílias envolvidas com o tráfico de drogas, violência cotidiana, entre outras condições de risco, e nesta empreitada entra a formação indissociada da politização docente, que especificamente na questão da infância como eixo e possibilidade, indicam que os limiares podem e devem ser espaços de fervilhar a imaginação, a criação e a transgressão dos saberes.

Um dos saberes mais presentes e cristalizados nas escolas em territórios precarizados, seriam as precárias condições de aprendizagem dos alunos e os fantasmas do fracasso escolar, amalgamando as precariedades dos alunos, professores e escola, mas em sentido inverso, podemos também construir olhares transgressores, que se atenham nas resistências, permanências e possibilidades para ver práticas concretas de educação e cuidado nas condições dadas, que são precárias dependendo do ponto de vista e expectativa, mas também politizadas e críticas apresentando indícios importantes do processo formativo (ressaltando nos diferentes níveis e estágios: de base, continuada, permanente) das professoras nos anos iniciais.

E a partir destas proposições, destaco uma importante referência destas relações do trabalho docente nos limiares da infância na escola, "No Olh@res, Guarulhos, v. 2, n. 2, p.375-404 . Dezembro, 2014. 
coração da sala de aula: gênero e trabalho docente nas séries iniciais" (1999) de Marília Pinto de Carvalho, resultados de pesquisas realizadas na década de 1990 em escolas públicas da periferia de São Paulo, apontando as relações de gênero como categoria de análise para compreender as professoras primárias como sujeitos históricos, que reproduzem as desigualdades presentes na escola, mas também resistem e apontam possibilidades de novas práticas pedagógicas.

Com especial destaque para a gestão do cuidado, como indissociável ao processo educativo ${ }^{7}$, distinto a práticas assistencialistas que podem até ser complementares em alguns contextos, mas o cuidado compreendido em outra perspectiva, como afirma a pesquisadora,

Talvez assim pudéssemos nos aproximar de uma situação em que as crianças de todas as camadas sociais fossem cuidadas de forma abrangente pelo menos na escola e na família, com qualidade, numa responsabilidade partilhada e compreendida como compromisso social; e numa relação de "cuidado" que não significasse opressão, desgaste, desqualificação ou culpa para quem cuida, seja homem ou mulher, na família ou em espaços institucionais. Essa é uma utopia, porém, que a presente ênfase das políticas educacionais na técnica, eficiência e competitividade, a serem alcançados com economia de recursos financeiros, está tornando ainda mais distante. (CARVALHO, 1999, p. 235)

Mesmo o fragmento denotando um tom de pessimismo da razão, o trabalho como um todo me remete a célebre máxima de Gramsci: $o$ otimismo da vontade, e a partir disto estes olhares nos limiares da infância, como eixo, possibilidade, são disparados nos encontros com as professoras

\footnotetext{
${ }^{7} \mathrm{Na}$ dimensão apontada pela pesquisadora Ana Maria Santana (1999) em Educação e Assistência: direitos de uma mesma criança, que traz o processo histórico da Educação Infantil no Mato Grosso a partir dos anos 80, apresentando importantes reflexões para a importância do cuidado em uma dimensão educativa, fortalecendo qualitativamente o binômio cuidar e educar como indissociável e indispensável para a conquista dos direitos das crianças. Cabe ressaltar que este debate é intenso e indispensável no campo da educação infantil (ROCHA, 1999; CERISARA, 1999, SOUZA, 2008, CAMPOS, 2011), porém nos anos iniciais, é ainda muito incipiente o debate.
}

Olh@res, Guarulhos, v. 2, n. 2, p.375-404 . Dezembro, 2014. 
A infância no limiar: eixo, inspiração e princípios na formação continuada e permanente das/os professoras/e da educação

nas suas relações com as crianças, entre elas, as estagiárias, com a escola e a educação.

Nesta dimensão do otimismo da vontade, compreendo o estágio nos anos iniciais na UFSC, em seu movimento de proporcionar e valorizar a experiência formativa no curso de pedagogia a partir do seu campo de estágio em escolas públicas que atendem territórios precarizados, tendo $a$ escola como organização complexa, assim como nos ensinou Mauricio Tragtenberg (1982), sendo uma importante possibilidade de articulação da formação de base - com as estudantes e com a continuada - com as professoras em exercício na perspectiva da sempre necessária e urgente politização docente.

Politização docente para as imprescindíveis reflexões sobre os processos históricos que produzem as desigualdades e perversidades estruturais no Brasil, para além das escolhas e fracassos atribuídos aos sujeitos escolares, destacando o quão fundamental para as professoras e professores das escolas públicas brasileiras é compreender as complexidades, contradições e possibilidades do trabalho docente com e para as crianças em condições de risco.

Professoras de educação infantil nos anos iniciais: a pedagogia das relações, da maravilha e da infância contagiando o cotidiano escolar

No contato com a escola, duas professoras se destacaram no que diz respeito as suas práticas com as crianças, para além do bom trabalho com os alunos, tanto pela relação de afeto e/ou de respeito a produção e presença das crianças.

Uma docente efetiva acompanhou o estágio no semestre passado e a outra compõe o quadro de professoras efetivas que iniciaram neste ano letivo, a primeira está no segundo ano, na escola e com a turma do $2^{\circ}$, era a professora do $1^{\circ}$ ano e a outra está com o $4^{\circ}$ ano. Ambas são jovens professoras de educação infantil há alguns anos (média de 10 anos de tempo de serviço) 'experimentando' a docência nos anos iniciais, a partir

Olh@res, Guarulhos, v. 2, n. 2, p.375-404 . Dezembro, 2014. 
da convocação do concurso do estado que foram aprovadas, anteriormente trabalhavam na Educação Infantil como ACT na rede municipal.

A professora $\mathrm{V}$. do $1^{\circ}$ ano contagiou a escola em 2013 com uma pedagogia da maravilha, remetendo no meu olhar interpretativo as inspirações e princípios da pedagogia da infância: centrada nas crianças, tendo o espaço físico como um $2^{\circ}$ educador e buscando um movimento pedagógico que proporcione a produção das culturas infantis. Através de um trabalho com as crianças na perspectiva da infância na escola, como ela mesmo define, em um primeiro momento disse que sentiu-se apavorada com a dimensão espacial da escola que assusta ${ }^{8}$, mais do que acolhe como é na educação infantil, em especial esta escola, como salientando anteriormente situada em um território precarizado, de certa forma reflete os conflitos e contradições do seu território, ou seja a escola é cercada, farpada, gradeada, mas também um espaço de possibilidades, com quadra, biblioteca, parque e uma vista privilegiada da baía sul de Florianópolis.

E seu trabalho foi pensando a partir justamente da organização do espaço, considerando-o como um $2^{\circ}$ educador e possibilitando o movimento das crianças e dos conhecimentos produzidos junto as crianças, também a professora $\mathrm{V}$. destaca que muito destas possibilidades foram materializados pelo apoio da escola a partir da formação no PNAIC (Programa Nacional de Alfabetização na Idade Certa) do governo federal, que junto a legislação do Ensino Fundamental de 9 anos vem possibilitando repensar os anos iniciais na perspectiva das crianças, com um ensino-aprendizagem que valorizem as dimensões da infância, através das brincadeiras, do lúdico e dos jogos, inclusive a mesma aponta que vem participando e gostando da formação oferecida em Santa Catarina.

A professora E. do $4^{\circ}$ ano, também salienta a importância do espaço em movimento, também destacando a sua trajetória e formação na

\footnotetext{
${ }^{8}$ A escola tem uma estrutura física complicada, deteriorada e com muitas grades, é um prédio antigo (de 1975) e embora ajam esforços das professoras que estão atuando na coordenação pedagógica e da direção em melhorar o espaço físico em um primeiro momento efetivamente assusta, apesar de que cabe ressaltar que muitos espaços de Educação Infantil também assustam pelas condições estruturais precárias para o atendimento à crianças pequenas e bem pequenas.

Olh@res, Guarulhos, v. 2, n. 2, p.375-404 . Dezembro, 2014.
} 
educação infantil, em uma situação com as estagiárias do $5^{\circ}$ ano em um momento de planejamento na sala das/os professoras/es, onde discutíamos as dificuldades encontradas e enfatizadas pela professora regente em sala, ela ‘solidariamente' fez algumas sugestões, a primeira e fundamental, seria algo no sentido de transgredir a 'forma escolar' (FREITAS, 2007) cristalizada e sedimentada nas parcas estratégicas de controle da 'bagunça' das crianças em sala, buscando negociar com as crianças o espaço e o tempo na escola, fazendo os combinados e garantindo os direitos das crianças de brincarem e interagirem entre si e de aprenderem concomitantemente, brincando, participando e criando situações de aprendizagem individuais e coletivas.

Ambas professoras buscam construir estratégias de formação continuada na escola, nos limiares das relações que nos formam permanentemente no campo educativo, entre elas, com as crianças e as professoras que estão na coordenação pedagógica, potencializando os interstícios de encontros entre as aulas, ou nos momentos de planejamento nas aulas de artes e educação física que não estão com as crianças.

Mas, sobretudo pude observar que estas professoras na minha percepção contagiam a escola na relação que estabelecem no espaço para além de fábulas (carta de intenções dos documentos legais), perversidades (sem as condições materiais), mas como possibilidades (SILVA e BUFALO, 2011), evidenciando o respeito à infância na escola que perpassam as práticas pedagógicas que constroem para, com e das crianças que estão seus alunos e alunas.

Nesta perspectiva de evidenciar os desafios do espaço físico como fundamental na conquista de direitos das crianças na escola, cabe destacar $\mathrm{o}$ artigo $O$ ensino fundamental de nove anos e o direito à educação (ARELARO, JACOMINI E KLEIN, 2011) que aponta,

Questionada sobre se a escola de ensino fundamental estava preparada para receber as crianças de 6 anos, uma professora afirmou: [...] não, começando pela mobília, todos ficaram com os pés suspensos. É totalmente inadequado, alguns dependurados na carteira. A escola regular hoje está preparada para alunos

Olh@res, Guarulhos, v. 2, n. 2, p.375-404 . Dezembro, 2014. 
maiores, ela não tem a característica de continuidade da infância. (Professora da rede estadual paulista) (p. 47)

As análises evidenciam que as rupturas continuam postas, mas na relação com a formação continuada e permanente com as professoras é possível descobrir e sonhar com possíveis pontes.

Formação continuada e educação permanente do sensível: espaço, tempo e infâncias

Como criancista e criancóloga, no Gepedisc Culturas Infantis construi minhas lentes, tendo como referências o tripé das pesquisas, das políticas e práticas (FARIA, 2005), bem como alimentada pelas publicações coletivas do grupo, que na perspectiva do ensino, pesquisa e extensão, entre outras destaco do "Coletivo Infantil em creches e préescolas: falares e saberes" aos "Territórios da Infância: linguagens, tempos e relações para uma pedagogia para as crianças pequenas" (ambos de 2007) passando "Por uma cultura da infância: metodologia de pesquisa com crianças" (2009) às "Culturas infantis em creches e préescolas: estágio e pesquisa" (2011) e lançei meus olhares sobre a formação continuada nas redes municipais de educação infantil de São José e Florianópolis.

Nestas publicações, entre outras, encontramos alguns dos mais importantes fundamentos teóricos de uma pedagogia da infância em movimento, buscando suas relações nos limiares efervescentes da arte e das ciências, assim como de uma infância sem tantas amarras cronológicas, que se situe para além da educação infantil como $1^{\mathrm{a}}$ etapa da educação básica ( 0 a 5 anos e 11 meses), uma pedagogia 0 a 10, 12 anos como prevê o Estatuto da Criança e do Adolescente, o ECA; contribuindo e apostando em uma sociologia da infância brasileira, construindo uma pedagogia macunaímica, com inspirações antropofágicas em busca de pedagogias descolonizadoras. 
Também neste movimento da pedagogia e das infâncias em movimento cabe ressaltar o importante trabalho de Eloisa Rocha (1999, 2000) e suas reflexões sobre as especificidades da pedagogia da educação infantil (0 a 5), campo em construção assim como das aproximações, distinções e possibilidades da pedagogia da infância (0 a 10).

Currículo e Infância caminhos possíveis na rede municipal de São José

Considerando este tempo e espaço da infância como norte ao nosso olhar, para refletirmos sobre a formação continuada e permanente do sensível, pensemos no município de São José que se situa na região metropolitana de Florianópolis, conurbado com a capital catarinense e possui, segundo estimativa do IBGE em 2013, uma população de 224.779 habitantes, sendo o quarto município mais populoso do estado, atrás de Joinville, Florianópolis e Blumenau, somados aos municípios vizinhos, ela forma a mais populosa região metropolitana de Santa Catarina com cerca de 1,049 milhão de moradores.

Sua rede de educação infantil possui Centros de Educação Infantil, os CEIs, muitos provenientes de associações comunitárias, bem como de instituições educativas de origem na e da EI, em uma rede em expansão com novas unidades sendo construídas e as velhas em constantes reformas, em um movimento para adequarem-se aos Critérios para atendimento em creche que respeite os direitos fundamentais das crianças. (2009)

A formação continuada na rede municipal de Educação Infantil em São José proposta pela prefeitura, também se situa nestes limiares dos avanços e retrocessos, com uma trajetória iniciada em 2000, com a publicação da $1^{\circ}$ síntese da proposta curricular/2000, que desencadeou posteriormente nos Cadernos Pedagógicos/2008, em 2010 e 2011 buscouse articular um documento orientador para a construção coletiva de suas Orientações Curriculares e em 2014 iniciou-se o ano letivo com uma proposta de formação intitulada, Currículo e Infância: caminhos possíveis. Olh@res, Guarulhos, v. 2, n. 2, p.375-404 . Dezembro, 2014. 
Buscando articular pesquisadoras/es e professores/as como assessores em uma intencionalidade da formação promover a produção coletiva de subsídios curriculares a Secretaria de Educação/SME por meio do Depto de Educação Infantil aposta em seu quadro de professoras/es e demais profissionais como sujeitos deste processo da rede e seu currículo em construção, caminhando na direção que algumas pesquisadoras da educação infantil nos indicam como possibilidades,

O debate sobre currículo na educação infantil é um desafio para as professoras e demais profissionais (direção, coordenação e apoio) que atuam com as crianças pequenas, mas também para as universidades e os cursos de formação docente para essa etapa educacional. Quais os princípios norteadores do currículo? Como organizá-lo? Como pensar os temas, tempos, espaços, atividades e materiais? (AQUINO \& VASCONCELLOS, 2012, p. 74)

Tendo encontros semanais com as professoras, em três grupos distintos, de seis CEI's (Centro de Educação Infantil) em média e um conjunto de no máximo 90 profissionais, entre professoras/es e algumas coordenadoras pedagógicas, tive a oportunidade de trabalhar com a temática das relações sociais e culturais, e partir dos primeiros encontros diagnósticos onde pude a partir dos relatos das professoras eleger como foco as relações de gênero e étnico raciais.

Discutindo conceitos e pesquisas, partindo de referências clássicas na área como das publicações da Fundação Carlos Chagas, com destaque para o texto Educação Infantil: classe, raça e gênero (1996) de Fúlvia Rosemberg, passando pelas contribuições de Deborah Sayão (2003) Pequenos homens, pequenas mulheres? Meninos, meninas? Algumas questões para pensar as relações entre gênero e infância, artigo publicado em um Dossiê no contexto do GEPEDISC - Culturas Infantis sobre Educação Infantil e Gênero as interlocuções mais recentes como as abordadas no artigo de Daniela Finco e Fabiana Oliveira (2011) $A$ 
A infância no limiar: eixo, inspiração e princípios na formação continuada e permanente das/os professoras/e da educação básica

sociologia da pequena infância e a diversidade de gênero e de raça nas instituições de educação infantil.

Nesta experiência muito enriquecedora, de profundo respeito e admiração pelas professoras de educação infantil deste município ${ }^{9}$, tive a oportunidade de se inspirar e sensibilizar-se na perspectiva do poema "Posso entrar com a girafa?" do professor de crianças, gestor público de educação e um dos fundadores da pedagogia da infância italiana (SILVA e FARIA, 2013), Loris Malaguzzi, escrito numa jornada de formação com educadoras infantis de San Miniato, na região Toscana da Itália e publicado após sua morte na revista Bambini, conforme Ana Lúcia Goulart de Faria nos apresentou em "Loris Malaguzzi e os direitos das crianças pequenas” (2007).

\section{Posso entrar com a girafa?}

A girafa tem o coração longe dos pensamentos

Se apaixonou ontem e ainda não sabe...

Não sendo uma girafa, Não tendo o coração longe dos pensamentos, Não estando apaixonado,

sei perfeitamente que força de amor envolve as coisas, as palavras, os fatos, as obrigações e as inteligências que tomaram vocês nestes dias fabricando jornadas de grande deleite e cultura em torno de uma empreitada que honra San Miniato, a infância, as nossas creches e as cultura infantis.

Agora a girafa percebeu que está apaixonada

Recolocando o coração perto dos pensamentos.

E está com vocês. E está comigo.

\section{Loris Malaguzzi}

\footnotetext{
${ }^{9}$ Experiência esta encerrada com um grande seminário de socialização com todas/os as professoras de Educação Infantil da rede municipal (em torno de 900 professoras), realizado no dia 25/11/2014, proporcionando um rápido e evidente retorno da formação continuada, evidenciado ao destacar em vários momentos que o dia 25/11 é o "Dia Mundial de combate a Violência contras as mulheres", inclusive os grupos que trabalhei numa perspectiva feminista (da práxis), produziram um folder (entregue a todas/os participantes) com história da data, dados sobre a violência doméstica, informações e possibilidades de denúncia, indicando uma rede de apoio intersetorial (saúde, educação, assistência social e segurança).
}

Olh@res, Guarulhos, v. 2, n. 2, p.375-404 .Dezembro, 2014. 
O espaço e tempo na educação infantil na rede municipal de Florianópolis

De alguma forma, sinto-me como a girafa apaixonada entre as/os professoras/es de Educação Infantil de São José, assim como das que encontrei em Florianópolis, onde iniciei a formação continuada posteriormente, subsidiada pelas "Orientações Curriculares para a Educação Infantil da rede municipal de Florianópolis”, publicadas em 2012, mas que vem sendo construída também há mais de uma década, como nos aponta os "Princípios pedagógicos para a Educação Infantil", ROCHA (2000), tendo em suas orientações curriculares como eixo estruturante as brincadeiras e os núcleos de ação pedagógica nas relações sociais e culturais e nas múltiplas linguagens e para a proposta de formação continuada em 2014 o tema 'O espaço e o Tempo na Educação Infantil'

Eloisa C. Rocha, pesquisadora e docente do CED/UFSC, também consta na autoria destas Orientações, junto com outras professoraspesquisadoras, sendo autora da tese de doutorado " $A$ Educação Infantil no Brasil: trajetória recente e perspectiva da consolidação de uma pedagogia da educação infantil" (1999), realizou o primeiro estudo da arte sobre a educação infantil brasileira, tornando-se uma referência para pensar este campo, da pedagogia da infância em construção, sendo ela também importante colaboradora das construções curriculares e formações continuadas em Florianópolis.

Trabalhar no contexto da formação continuada com professoras de uma rede situada em uma ilha, belíssima, conhecida como a ilha da magia, tendo como tema $\mathrm{O}$ espaço e o tempo na Educação Infantil lançou-me no mais precioso dos limiares, que é da arte com as ciências, selecionando para um primeiro encontro um velho 'amigo' e inspiração constante: o Palomar de Italo Calvino (1994).

Palomar é o nome de um famoso observatório astronômico que durante muito tempo ostentou o maior telescópio do mundo. Por intencional ironia, é também o

Olh@res, Guarulhos, v. 2, n. 2, p.375-404 . Dezembro, 2014. 
A infância no limiar: eixo, inspiração e princípios na formação continuada e permanente das/os professoras/e da educação

nome do protagonista destes textos curtos de Italo Calvino, pois este senhor Palomar é todo olhos, mas funciona quase sempre como se fosse um telescópio ao contrário, voltado não para a amplidão do espaço, mas para as coisas próximas do cotidiano. É como se ele nos dissesse que as grandes questões do mundo e da existência também estão presentes em cada objeto que observamos, em cada cena que presenciamos, e que tudo é digno de ser interrogado e pensado. ${ }^{10}$

Palomar na praia: leitura de uma onda inspirou e animou o primeiro encontro da formação continuada 2014, com mais de 80 professoras do grupo 3 (das crianças pequenas, entre 2 a 3 anos) de diversas creches e Núcleos de Educação Infantil de toda a rede, da ilha e dos bairros na parte continental. Com uma dinâmica de leitura coletiva busquei trazer elementos da observação, do mar, das crianças e do cotidiano que despertassem suas sensibilidades e disponibilidade para este processo formativo que lança olhares sobre o espaço e o tempo em sua dinâmica, complexidade, contradição e possibilidade.

Uma das professoras contagiada pela poética de Palomar em sua síntese da leitura e discussão em grupo com as colegas escreveu:

...Há momentos que o mar está revolto e em segundos se torna manso...e nós como atentas observadoras delimitamos nosso olhar para então nos deparar com a infinita diversidade espacial, pessoal e de tempo, e então, nessa multiplicidade de momentos criar ações que amplie e contemple a todos. (V. C.V., N.E.I. João Machado da Silva, 6/ Maio/2014)

Outra referência para complementar esta experiência poética que problematiza o tempo-espaço, como as descritivas narrações de Palomar, problematizando para o contexto da Educação Infantil, foi inspirada pelo trabalho de Maria Carmem Barbosa (2012) e suas reflexões sobre a organização da vida cotidiana das crianças, suas famílias e professoras/es. A pesquisadora aponta,

\footnotetext{
${ }^{10}$ Conforme site da Cia das Letras. http://www.companhiadasletras.com.br/ Olh@res, Guarulhos, v. 2, n. 2, p.375-404 . Dezembro, 2014.
} 
Talvez o tempo seja o tema fundamental para ser discutido nas propostas de organização da vida cotidiana da educação infantil, pois ele é uma categoria política que diz respeito à vida das crianças, de seus pais e também de seus professores. Tempo acelerado, tempo do capital; Tempo para estar juntos; Brincar é a capacidade de inventar mundos; Narrar a vida, viver as narrativas; Encontrar, brincar e narrar: estratégias para romper a aceleração do tempo. (BARBOSA, p. 9, 2012)

Nesta perspectiva de narrar a vida e viver as narrativas, no decorrer dos meses de encontro com as professoras, busquei abordar aspectos que pesquisei em meu doutorado (SILVA, 2014) sobre a estética da infância no cinema, as poéticas e culturas infantis para refletir dos desafios da docência na pequena infância de se apropriar do tempo em sua dimensão política, evidenciando nas discussões o quanto a estética, na sua dimensão política de partilha do sensível (RANCIERE, 2005) está associada à ética e são constructos históricos culturais, criações humanas, em movimento no tempo e no espaço.

Assim como as perspectivas feministas ${ }^{11}$ das relações culturais e sociais que abordei ao longo da formação continuada em São José, também animaram os encontros com a rede em Florianópolis, esta ainda repleta de narrativas mágicas com as histórias de bruxas de Franklin Cascaes (2012) e possibilidades transgressoras de inventar outros mundos e lugares históricos para as mulheres e as professoras de educação infantil.

\section{Para não concluir... a infância nos limiares da formação das/os professoras/es: pesquisa, políticas e práticas de resistência}

\footnotetext{
${ }^{11}$ E ainda contagiada com o 25/11 cito uma matéria publicada na data citada, na revista Carta Capital que diz: "De uma forma geral, pode-se dizer que o objetivo do feminismo é uma sociedade sem hierarquia de gênero: o gênero não sendo utilizado para conceder privilégios ou legitimar opressão. Ou como disse Amelinha Teles na introdução de Breve história do feminismo no Brasil, "falar da mulher, em termos de aspiração e projeto, rebeldia e constante busca de transformação, falar de tudo o que envolva a condição feminina, não é só uma vontade de ver essa mulher reabilitada nos planos econômico, social e cultural. É mais do que isso. É assumir a postura incômoda de se indignar com o fenômeno histórico em que metade da humanidade se viu milenarmente excluida nas diferentes sociedades no decorrer dos tempos" http://www.cartacapital.com.br/blogs/escritorio-feminista/feminismo-academico-9622.html Acesso em 25/11/2014.
}

Olh@res, Guarulhos, v. 2, n. 2, p.375-404 . Dezembro, 2014. 
A intencionalidade nas reflexões apresentadas neste texto, repleto de limiares fervilhantes de imaginação, invenção e transgressão vem do desejo de evidenciar um movimento e processo de formação de professoras/es na perspectiva da pesquisa, políticas e as práticas em uma dimensão da resistência, sobretudo ao tempo das dicotomias que separam as crianças da educação infantil dos alunos dos anos iniciais do ensino fundamental.

Lançar olhares sobre a formação continuada nas redes de educação infantil citadas, também se configura neste processo permanente de descolonizar o pensamento sobre a formação continuada, esta como bem problematizada por Helena de Freitas (2002, 2007) configura-se historicamente como uma política de carta de intenções, marcada com embates de projetos distintos de formação e constantemente como uma prioridade postergada.

Postergada também como é os direitos das crianças de viverem suas infâncias, sobretudo na primeiríssima infância (dos 0 a 6 anos) em um espaço e tempo criado para e com elas: a creche, marcado por uma luta histórica do movimento feminista (FARIA, 2005), salientando um projeto político de transformação da sociedade e de combate das desigualdades de gênero na divisão sexual do trabalho e na responsabilidade coletiva da educação/cuidado das crianças.

Porém para finalizar que o espaço indissociado do tempo também mensura as reflexões, sobretudo as transgressoras, apesar dos tempos sombrios $^{12}$, retomo o tempo do brincar e narrar, reforçando que sinto-me apaixonada como a girafa mallaguziana, uma vez que no trabalho nos limiares fervilhantes da formação continuada das professoras, realizadas em suas horas atividades, uma conquista destas redes e suas docentes, assim como este direito à formação para, junto com elas/eles e suas crianças pequenas, pequenininhas, bebês, de São José e Florianópolis, estas redes estão resistindo a pacotes prontos de formação apostiladas.

\footnotetext{
${ }^{12}$ Sombrios de antecipações, obrigatoriedades, avaliações apostiladas...

Olh@res, Guarulhos, v. 2, n. 2, p.375-404 . Dezembro, 2014.
} 
Reinventando os tempos e espaços, nestas jornadas de grande deleite e cultura, onde é possível realimentar o otimismo da vontade citado anteriormente, sentindo a indissociabilidade da razão e da emoção, que aproxima o coração dos pensamentos em torno da infância, das escolas de ensino fundamental às creches, centros e núcleos de educação infantil e das culturas infantis.

Olh@res, Guarulhos, v. 2, n. 2, p.375-404 . Dezembro, 2014. 
A infância no limiar: eixo, inspiração e princípios na formação continuada e permanente das/os professoras/e da educação básica

\section{Referências bibliográficas}

AQUINO, Ligia Maria Leão de \& VASCONCELLOS, Vera M. Ramos. Questões curriculares para educação infantil $e$ PNE. In AQUINO, Ligia. Maria L. \& FARIA, Ana Lúcia G.(Orgs.) Educação Infantil e PNE: questôes e tensões para o século XXI. Campinas, SP: Autores Associados, 2012.

ARELARO, Lisete. JACOMINI, Marcia. A., KLEIN, Sylvie. O ensino fundamental de nove anos e o direito à educação. Educação e Pesquisa, São Paulo, v.37, n.1, 220p. 35-51, jan./abr. 2011.

BARBOSA, Maria Carmem S. Tempo para viver o Cotidiano In Revista Pátio Educação Infantil, Ano X, julho/setembro 2012.

BARRENTO. João. Limiares sobre Walter Benjamim. Florianópolis: Ed. UFSC, 2014.

BENJAMIN, Walter. Reflexões: a criança, o brinquedo, a educação. São Paulo: Summus Editorial, 1984.

CALVINO, Italo. Palomar. São Paulo: Cia da Letras, 1994.

CERISARA, Ana Beatriz. Educar e cuidar: por onde anda a educação infantil? Revista Perspectiva do Centro de Educação da UFSC. V. 17, n. Especial, p. 11-21. jul/dez. 1999.

CAMPOS, Roselane F. Educação infantil. Políticas e identidade. Revista Retratos da Escola, Brasília, v. 5, n. 9, p. 217-228, jul./dez. 2011.

CARVALHO, Marília Pinto de. No coração da sala de aula: gênero e trabalho docente nas séries iniciais. São Paulo: Xamã, 1999.

CASCAES, Franklin. O fantástico na Ilha de Santa Catarina. Florianopolis: Editora da UFSC, 2012.

Olh@res, Guarulhos, v. 2, n. 2, p. 375-404. Dezembro, 2014. 
DANTAS, Jefferson S.; PINTO, Fábio M.; MARCASSA, Luciana P. (Orgs.) Formação Continuada e Politização Docente: escola e universidade na luta pela educação no Maciço do Morro da Cruz - Florianópolis: Ed. Insular, 2013

FARIA, Ana Lúcia Goulart. Loris Malaguzzi e os direitos das crianças pequenas. In: Oliveira-Formosinho, Júlia; Kishimoto, M. Tizuko e Pinazza, A. Mônica (Orgs.) Pedagogia(s) da Infância: dialogando com o passado: construindo o futuro. Porto Alegre: Artmed, 2007.

. Políticas de regulação, pesquisa e pedagogia na educação infantil, primeira etapa da educação básica. In Revista Educação \& Sociedade, Faculdade de Educação/UNICAMP, Campinas, SP, v. 26, p. 1013-1038, 2005.

FARIA, Ana Lúcia G.; MELLO, Suely A. (Orgs.) Territórios da Infância: linguagens, tempos e relações para uma pedagogia para as crianças pequenas. Araraquara, SP: Junqueira\&Marin, 2007.

FARIA, Ana Lúcia G.; DEMARTINI, Zeila de B.; PRADO, Patrícia D. Por uma cultura da infância: metodologias de pesquisa com crianças. Campinas, SP: Autores Associados, 2009

FINCO, Daniela; OLIVEIRA, Fabiana. A sociologia da pequena infância e a diversidade de gênero e de raça nas instituições de educação infantil. In Sociologia da infância no Brasil , Editora Autores Associados, Campinas/SP, p. 55-80, 2011.

FLORIANÓPOLIS. Orientações Curriculares para a Educação Infantil da rede municipal de Educação Infantil de Florianópolis. Secretaria Municipal de Educação de Florianólis., PMF, SMF, Florianopólis, SC: Prelo, 2012.

FREITAS, Helena Costa L. Formação de professores no Brasil: 10 anos de embate entre projetos de formação. Educação e Sociedade. Campinas, v. 23, n.80, p. 136-167, set. 2002. 
A nova política de formação de professores: prioridade postergada.

Educação e Sociedade. Campinas, v. 28, n.100 - Especial, p. 1203-1230, out. 2007.

FREITAS, Marcos C. O Coletivo infantil: o sentido da forma. In FARIA, Ana Lúcia G. (Orgs.) $O$ Coletivo infantil em creches e pré-escolas: falares e saberes. SP: Cortez, 2007.

KISKIMOTO, Tizuko M. Pedagogia e a formação de professores(as) de Educação Infantil. Pro-Posições, v. 16, n. 3 (48) - set./dez. 2005

MELLO, Suely Amaral de. Infância e Humanização: algumas considerações na perspectiva histórico cultural. In Dossiê Infância, educação e escola, Revista Perspectiva do Centro de Educação da UFSC. V. 25, n. 1, janeiro/junho 2007, p. 83-104.

NASCIMENTO, Maria Letícia B. P. As políticas públicas de educação infantil e a utilização de sistemas apostilados no cotidiano de creches e pré-escolas públicas. Revista Brasileira de Educação v. 17 n. 49 jan.-abr. 2012.

PIMENTEL, Maria Elisa C. $O$ Direito à infância na escola: o estágio docente como campo de pesquisa. Dissertação de Mestrado. CED/UFSC, Florianópolis, 2014.

QUINTEIRO, Jucirema; CARVALHO, Diana de C. (Orgs.) Participar, Brincar e Aprender: exercitando os direitos da criança na escola. Araraquara, SP: Junqueira\&Marin; Brasília, DF: CAPES, 2007.

QUINTEIRO, Jucirema. Infância e Escola: uma relação marcada por preconceitos. Tese de Doutorado (Ciências Sociais aplicadas à Educação) em Educação. Faculdade de Educação/UNICAMP, 2000.

RANCIÈRE, Jacques. A partilha do sensível: estética e política. São Paulo: Editora 34, 2005 
ROCHA, Eloisa Acires C. A Educação Infantil no Brasil: trajetória recente e perspectiva da consolidação de uma pedagogia da educação infantil. Tese de Doutorado (Ciências Sociais aplicadas à Educação) em Educação. Faculdade de Educação/UNICAMP, 1999.

. Princípios pedagógicos para a Educação Infantil. Secretaria Municipal de Educação de Florianólis (Org.) Subsídios para a Reorganização Didática da Educação Básica Municipal. 1 ed. PMF, SMF, Florianopólis, 2000, v. 1, p. 52-65.

ROSEMBERG, Fúlvia. Educação infantil, classe, raça e gênero. São Paulo, Cadernos de pesquisa, n. 96, fev. 1996, p. 58-65.

SAYÃO, Deborah Thomé de. Pequenos homens, pequenas mulheres? Meninos, meninas? Algumas questões para pensar as relações entre gênero e infância. (pgs. 6787) In Dossiê: Educação Infantil e Gênero, da Revista Pro-posições, Faculdade de Educação/UNICAMP, Campinas, SP, v. 14, n. 3 (42), set/dez. 2003.

SÃO JOSÉ. Proposta Curricular da Rede Municipal de Ensino de São José: uma primeira síntese 2000. São José: Secretaria de Educação e Cultura, 2000.

Caderno Pedagógico. Rede Municipal de Ensino de São José. Educação Infantil. São José: Prefeitura Municipal d e São José: Secretaria Municipal de Educação/Setor Pedagógico, 2008.

SANTANA, Anamaria. Educação e Assistência: direitos de uma mesma criança. ProPosições, vol. 10, nº 1 (28), p. 40-53, março de 1999.

SILVA, Adriana; BUFALO, Joseane. O espaço na pedagogia da educação infantil: fábula, perversidade e possibilidade. In Culturas infantis em creches e pré-escolas: estágio e pesquisa. Campinas, SP: Autores Associados, 2011.

SILVA, Adriana A.; FARIA, Ana Lúcia G. Por uma nova cultura da infância: Loris Malaguzzi. Revista Educação Especial, v. X, p. 98-111, 2013. Olh@res, Guarulhos, v. 2, n. 2, p. 375-404. Dezembro, 2014. 
A infância no limiar: eixo, inspiração e princípios na formação continuada e permanente das/os professoras/e da educação básica

SILVA, Adriana A. A Estética da Infância no Cinema: poéticas e culturas infantis. Tese de Doutorado em Educação, Faculdade de Educação, UNICAMP, Campinas, 2014.

SOUZA, Gizele. Educação da infância - estar junto sem ser igual: Conflitos e alternativas da relação da educação infantil com o ensino fundamental! Educar, Curitiba, n. 31, p. 17-31, 2008.

TELES, Maria Amélia de A. Breve História do feminismo no Brasil. São Paulo: Brasiliense, 1999.

TRAGTENBERG, Maurício. A escola como organização complexa. In: Sobre educação, política e sindicalismo. São Paulo: Autores Associados e Cortez, 1982 